\title{
Child neglect and its relation to emotional and behavioral problems: A cross-sectional study of primary school-aged children in Tanzania
}

\author{
TOBIAS HECKER,,$^{a, b}$ VICTORIA S. BOETTCHER, ${ }^{a}$ MARKUS A. LANDOLT, ${ }^{b, c, d}$ AND \\ KATHARIN HERMENAU ${ }^{b, e}$ \\ ${ }^{a}$ Bielefeld University; ${ }^{b}$ vivo international; ${ }^{c}$ University Children's Hospital Zurich; ${ }^{d}$ University of Zurich; and ${ }^{e}$ University of \\ Konstanz
}

\begin{abstract}
Child maltreatment is known to engender negative emotional and behavioral consequences. Although neglect is the most frequent form of maltreatment, it has thus far only received little attention, especially when looking at low-resource countries. The current study investigated possible associations between neglect and internalizing and externalizing problems. As neglect and abuse often co-occur, the latter was controlled for. In total, 409 Tanzanian primary school students ( $52 \%$ boys, $M=10.5$ years, range $=6-15$ ) participated in the cross-sectional study. Structured clinical interviews were conducted assessing maltreatment, internalizing problems, and externalizing problems. Overall, $31 \%(n=128)$ of the children reported at least one type of physical neglect and $31 \%(n=127)$ of emotional neglect. Using structural equation modeling, we found a significant association between neglect and internalizing $(\beta=0.59$, $p<.01)$ and externalizing problems $(\beta=0.35, p<.05)$. However, these associations could only be detected in younger children (ages $6-9)$, whereas in older children (ages 10-15), mental health problems were significantly related to violence and abuse. Our findings suggest that the current age may influence the association between maltreatment type and the development of internalizing and/or externalizing problems.
\end{abstract}

Child maltreatment, including physical, emotional, and sexual abuse, as well as emotional and physical neglect is a global phenomenon (Dubowitz \& Bennett, 2007; Stoltenborgh, Bakermans-Kranenburg, Alink, \& van IJzendoorn, 2015). It is defined as "any act or series of acts of commission or omission by a parent or other caregiver that results in harm, potential for harm, or threat of harm to a child" (Leeb, Paulozzi, Melanson, Simon, \& Arias, 2008, p. 11) and can result in several severe emotional, social, and cognitive consequences across the life span (Gilbert et al., 2009; Norman et al., 2012).

Compared to the definition of abuse, that of neglect is inconsistent and less clear in the research literature (Dubowitz et al., 2005; Jud, Lips, \& Landolt, 2010). Complicating the

This research was supported by the Deutsche Forschungsgemeinschaft and by the nongovernmental organization vivo international. We thank all of the children who participated in this study for their willingness to discuss intimate and painful subjects. We are very grateful to our highly motivated and reliable research team, including Manswab Geho, Dorothea Isele, Huruma Kipagile, Getrude Mkinga, Andrew Mtitu, Zephania Ngowi, Lulu Nziku, Astrid Pabst, Charlotte Salmen, and Leila Samson. We appreciated the statistical support of Daniel Seddig, Terrence D. Jorgensen, and Yves Rosseel. We also thank James Moran who critically reviewed the manuscript and Thomas Elbert for his continuous support.

Address correspondence and reprint requests to: Tobias Hecker, Department of Psychology, Bielefeld University, P.O. Box 100131, 33501 Bielefeld, Germany; E-mail: tobias.hecker@uni-bielefeld.de. search for a uniform definition may be the fact that neglect does not consist of clearly visible acts, such as actively harming someone. Instead, it contains acts of often invisible omission, which is the failure to act (Mennen, Kim, Sang, \& Trickett, 2010). Neglect exists on a continuum (Dubowitz, 2007, 2013), and defining a threshold where the failure to act becomes neglect has proven to be difficult (Dubowitz, 2013; Dubowitz et al., 2005; McSherry, 2007). Moreover, neglect includes a wide variety of different forms, such as in regard to the child's emotional needs or the child's physical health (McSherry, 2007). Neglect may occur for a variety of reasons, and parents or caregivers often do not intend to endanger the child (Dubowitz, 2013). It is more likely that they do not have the necessary resources, do not recognize the potential danger, or suffer from psychological ailments themselves (Dubowitz \& Bennett, 2007). This is of special importance with regard to low-resource countries, due to the high prevalence of difficult life circumstances (Mbagaya, 2010). However, the lack of a uniform definition makes determination of prevalence rates difficult (McSherry, 2007). In this paper, we define neglect as "the failure to provide for a child's basic physical, emotional, or educational needs or to protect a child from harm or potential harm" (Leeb et al., 2008, p. 17). Furthermore, we follow the common differentiation of neglect into physical and emotional neglect. Physical neglect includes omissions like the failure to provide properly fitting clothes that are appropriate to the weather, not taking the child 
to the doctor when he or she is ill, or not feeding the child properly. Emotional neglect, in contrast, includes omissions like not interacting with the child or not responding to the child's emotional needs (Barnett, Manly, \& Cicchetti, 1993).

Child neglect is known as a type of maltreatment with a chronic nature as it usually occurs repeatedly over a period of time (Korbin \& Krugman, 2014). It is the most common and the most frequently fatal form of child maltreatment (Korbin \& Krugman, 2014; US Department of Health and Human Services, 2012). In addition, recent studies have found that, in contrast to other types of maltreatment, the prevalence rates of neglect are not declining (Korbin \& Krugman, 2014). For example, Sedlak et al. (2010) conducted a community survey in the United States and came up with a frequency of 31 incidences of neglect per 1,000 children. Another estimate stated that $78 \%$ of child maltreatment reported to the US child welfare system in 2009 was for neglect (US Department of Health and Human Services, 2010). However, in spite of these estimations, little attention has been paid to neglect. This is particularly true for middle- and low-income countries. For example, a meta-analysis on the global prevalence of neglect could only include three studies from Asia but none from South America nor from Africa (Stoltenborgh et al., 2015; Stoltenborgh, Bakermans-Kranenburg, \& van IJzendoorn, 2013).

More than 30 years ago, Wolock and Horowitz (1984) were the first to term this phenomenon "neglect of neglect." Childhood neglect receives less consideration than other forms of maltreatment, with regard to research, public awareness, and money spent on prevention and treatment of neglected children (Korbin \& Krugman, 2014; McSherry, 2007), even though it often results in tremendous negative consequences (Dubowitz, 2013). However, these consequences may appear only years later (Dubowitz, 2007; Korbin \& Krugman, 2014), which might have the effect of making neglect appear less detrimental at first sight. Besides that, neglect often occurs together with other types of maltreatment, such as different types of abuse (Finkelhor, Ormrod, \& Turner, 2007; Korbin \& Krugman, 2014; Mennen et al., 2010). This co-occurrence makes it difficult to disentangle the consequences of neglect from consequences of other forms of maltreatment (Korbin \& Krugman, 2014). However, Mills et al. (2011) and Hildyard and Wolfe (2002) found that neglect in early childhood can have unique influences on social, emotional, cognitive, and physical development all the way into adolescence and adulthood.

\section{Childhood Neglect and Its Association With Internalizing Problems}

Several studies have found support for the association between childhood neglect and children's level of internalizing problems (Hildyard \& Wolfe, 2002; Manly, Kim, Rogosch, \& Cicchetti, 2001; Spratt et al., 2012). Comparing neglect with other types of maltreatment, Manly et al. (2001) discovered that neglected children tend to internalize problems significantly more than physically abused children do. They also found neglected children to be more socially withdrawn compared to nonneglected children. In their review, Hildyard and Wolfe (2002) presented further support for this finding: neglected children experience relatively few positive social interactions. In addition, they reported an association between neglect and problems in emotion regulation. These emotional problems also appeared to be more severe than those of abused children (Hildyard \& Wolfe, 2002). According to Widom, DuMont, and Czaja (2007), the risk of a diagnosis of depression is also increased in neglected children.

\section{Co-Occurrence of Abuse and Neglect}

Neglect has also been associated with externalizing problems. For example, Kotch et al. (2008) conducted a longitudinal study following children from birth until the age of 8. They discovered support for an association between early neglect and aggression later in life. Nevertheless, in another study, camp counselors rated neglected children as more aggressive compared to nonneglected children, but less aggressive than physically abused children (Manly et al., 2001). As neglect and abuse often co-occur, many studies fail to adequately disentangle the consequences of abuse and neglect. Widom and Maxfield (2001) found evidence for a significant association between maltreatment and violent criminal behavior when comparing arrest records of maltreated children with those of a control group. Furthermore, Widom et al. (2007) found an increased risk for later alcohol abuse in maltreated women compared to a nonmaltreated control group. However, in spite of these studies, it remains unclear whether the increased levels of externalizing problems are related to experiences of abuse, neglect, or both.

The same is also true for the consequences of abuse. Abuse has been consistently associated with externalizing problems (e.g., conduct disorder, hyperactivity, aggressive, and criminal behavior; Gershoff, 2002; Hecker, Hermenau, Isele, \& Elbert, 2014; Manly et al., 2001; Sugaya et al., 2012). Abuse has also be associated with internalizing problems (Hecker, Hermenau, Salmen, Teicher, \& Elbert, 2016a; Manly et al., 2001). However, most investigations of the consequences of child maltreatment focus only on exposure to violence, including abuse, and do not document whether they controlled for other types of maltreatment, such as neglect (Paolucci, Genuis, \& Violato, 2001). In addition, many studies did not differentiate between the different types of maltreatment at all (Danese \& Tan, 2014). Thus, in many cases, findings cannot be attributed clearly to either abuse or neglect.

In this context, the application of the developmental traumatology model (de Bellis, 2001) may be helpful. This model posits that traumatic stress resulting from child maltreatment adversely affects biological stress systems and brain development (e.g., in the amygdala and the hypothalamus-pituitaryadrenal axis). These alterations increase the risk for mental health problems, such as posttraumatic stress disorder, internalizing and externalizing disorders, personality disorders, or substance abuse as well as compromised cognitive and psy- 
chosocial functioning (de Bellis, 2001). The development traumatology model predicts that abuse may result in a deregulation of the stress response axis. The deregulated stress response makes children overly alert and show increased hyperarousal. These children are prepared to react to danger (i.e., with fight or flight reactions) at any moment. As a consequence, they are more likely to show outburst of anger, to feel provoked, and to get into fights than other children. These effects combined with social learning theory (Bandura, 1978; Hecker et al., 2014), which states that abused children learn from their abuser to solve conflict and demonstrate power with violent behavior, may predict that experiences of abuse will be particularly associated with externalizing problems of the affected children.

In contrast, learned helplessness (Abela, 2001; Abramson, Seligman, \& Teasdale, 1978) would suggest that neglected children develop helplessness-related cognitions and as a consequence become vulnerable to developing internalizing problems, such as social withdrawal or depressive symptoms. This idea was supported by findings of a prospective longitudinal study with a large community sample of children. The study found that neglect was associated with more internalizing problems, and that neglected children reported higher levels of perceived external control (Bolger \& Patterson, 2001). This was particularly true for children who have been neglected early in life. In turn, higher levels of perceived external control accounted substantially for associations between neglect and children's internalizing problems. Nonetheless, as the different types of maltreatment often co-occur, the range of symptoms of the affected children may, of course, be mixed in individual cases.

\section{Objectives}

In the current study, we focused on neglect as the most prevalent and at the same time most underestimated type of maltreatment (McSherry, 2007). A recent meta-analysis on the global prevalence of neglect has clearly indicated that most studies investigating neglect focused on samples emerging from what is defined by the International Monetary Fund (2007) as high-resource countries (Stoltenborgh et al., 2013). As developing countries make up a large part of the world, more research in these countries is highly important to understand child neglect and its consequences from a global perspective. In addition, the very few studies from sub-Saharan Africa focused on atrisk groups, such as orphans or other vulnerable children (e.g., Hermenau, Eggert, Landolt, \& Hecker, 2015; Morantz, Cole, Ayaya, Ayuku, \& Braitstein, 2013). So far, there has been no study that examined neglect in a large communitybased sample of children. Therefore, the first aim of this study was to examine the prevalence of neglect in a large community-based sample of children in Tanzania.

The literature on the consequences of neglect consistently showed that neglect can result in numerous severe consequences across the life span (Gilbert et al., 2009; Norman et al., 2012). Though there is consensus that maltreatment has negative consequences for children's mental health, the potential individual contribution of different types of maltreatment to distinct mental health problems is as yet unclear (Hildyard \& Wolfe, 2002). The deviating research findings could be explained by the fact that many studies did not control for the potential co-occurrence of abuse and neglect (Finkelhor et al., 2007). The second aim of the study was thus to examine the relationship between child neglect and behavioral and emotional problems in a large community-based sample of children. As it often co-occurs with exposure to violence and abuse, we controlled for these types of maltreatment (e.g., family violence, peer violence, and sexual abuse). Based on our theoretical consideration (see above), we hypothesized that in a sample of primary school-aged children (ages 6-15) from a low-income country, child neglect would be associated with internalizing problems but not externalizing problems, when controlling the influence of exposure to violence and abuse.

\section{Method}

\section{Participants}

A total of 409 children (52\% male) living in a small town in southern Tanzania participated in the study. They ranged from 6 to 15 years of age $(M=10.49, S D=1.89)$. All children were in the second to seventh year of formal schooling. The majority $(70 \%, n=288)$ indicated that they were living together in one household with their mother and/or their father. Eighteen percent $(n=75)$ of the children lived in institutional care or in foster families. Eighty-nine children (22\%) reported that at least one parent had died. These numbers are comparable to official figures from Tanzania reported by UNICEF (2011). According to these sources, in 2009, $20 \%$ of the boys and $25 \%$ of the girls were orphans.

\section{Procedure}

A team of five Tanzanian psychologists, two Tanzanian psychology students, as well as five psychologists from Germany conducted structured interviews with the children. The interviews took $1.5 \mathrm{hr}$ on average and were conducted in Swahili. Before carrying out the individual interviews, all interviewers took part in an interactive 2-week training session that included theoretical input and practice, such as role-plays of challenging interview situations. They were taught interview skills and how to conduct interviews with children. In addition, the different concepts assessed in the study, such as externalizing and internalizing problems, were studied. Finally, the principal investigators trained interviewers and translators in the interpretation of the interview responses from Swahili to English. The interview teams rotated constantly and consisted either of one German interviewer and one Tanzanian interpreter or one or two Tanzanian interviewers. The team leaders continuously supervised the team to ensure the interviews were carried out properly. Prior to the first interview, all instruments were translated into Swahili and were discussed 
to ensure a precise translation. A blind back-translation into English guaranteed correct translation. One of the German researchers was fluent in Swahili and could ensure valid translations. To test interrater reliability, two independent assessors rated 33 interviews.

The study was conducted in close cooperation with the Tanzanian school the children attended. Written informed consent forms, as well as letters explaining the study's purpose, were sent to all caregivers of the children of Grades 2 to 7 . The caregivers were informed that participation was voluntary and no monetary compensation would be provided. They were invited to ask further questions. Finally, only children whose parents or caregivers had signed and returned the informed consent form were included and interviewed. Following that, about $80 \%$ of the children could be included. Before the interview started, every child was verbally informed that he or she could end the interview at any time. In addition, the children were assured that everything they said to the interviewer would remain confidential. The interviews were conducted individually in a quiet setting in the school. A female interviewer interviewed girls. The Tanzanian Commission for Science and Technology as well as the Ethical Review Board of the University of Konstanz, Germany, approved the study.

\section{Measures}

All variables were assessed by means of a structured expert interview. This means that even young children could be included in the study. The interview started by collecting sociodemographic information such as age, grade, and gender.

Maltreatment. The Maltreatment and Abuse Chronology of Exposure-Pediatric Interview (pediMACE; Isele et al., 2017) was used to assess "neglect" and "exposure to violence." The pediMACE is the child-appropriate version of the Maltreatment and Abuse Chronology of Exposure (Teicher \& Parigger, 2015). The pediMACE contains 45 questions in total. In this study, we focused on the subsections assessing physical neglect (5 items), emotional neglect (3 items), violence and abuse in the family context (12 items), in the peer context ( 5 items), and sexual abuse ( 9 items; see Table 1). Only approval or negation of specific events was assessed, since the chances of a distorted memory regarding intensity or the number of occurrences are high (McNally, 2006). We calculated sum scores for both types of neglect by summing up all of the relevant question responses. The Cohen $\kappa$ coefficient for physical neglect measuring the interrater reliability was $>0.99(>0.99-1)$. For emotional neglect, the Cohen $\kappa$ coefficient was $0.96(0.88-1)$. Sum scores for each type of violence were calculated for further analysis. The Cohen $\kappa$ coefficient was $>0.99(>0.99-1)$ for violence in the family context, violence in the peer context, and sexual violence.

Internalizing and externalizing problems. Self-reported internalizing and externalizing behavior problems were assessed with the Strength and Difficulties Questionnaire (SDQ; Goodman, Meltzer, \& Bailey, 1998). The SDQ comes with good psychometric properties and has been used globally (Goodman, 2001). The questionnaire has been successfully implemented in Tanzanian settings before (Hermenau et al., 2011; Traube, Dukay, Kaaya, Reyes, \& Mellins, 2010). In the current study, the 25-item self-report version for children was used in interview form. The version consists of five subscales with 5 items each: conduct problems (e.g., "I am often accused of lying and cheating"), hyperactivity (e.g., "I am easily distracted; I find it difficult to concentrate"), emotional symptoms (e.g., "I am often unhappy, depressed, or tearful"), peer problems (e.g., "I get along better with adults than with people my own age"), and prosocial behavior (e.g., "I am kind to younger children"). The children had to choose between the answer opportunities $0=$ not true, $1=$ somewhat true, and $2=$ certainly true. Each subscale of the SDQ ranges from 0 to 10 . In the current sample, the Cohen $\kappa$ coefficient was 0.99 (0.94-1). The Cronbach $\alpha$ coefficient for the total difficulties score (all subscales except prosocial behavior) was 0.67 in the present sample. This moderate score can be explained by the total score's heterogeneity. In the current study, the emotional symptom subscale and the peer problem subscale were used to assess parts of internalizing problems. The Cohen $\kappa$ coefficient for the emotional symptom subscale was $0.99(0.95-1)$ and $>0.99(>0.99-1)$ for the peer problem subscale. The conduct problem subscale and the hyperactivity subscale were used to assess parts of externalizing problems. The Cohen $\kappa$ coefficient for the conduct problem subscale was 0.99 (0.94-1) and 0.99 (0.96-1) for the hyperactivity subscale. A score of 4 or higher on the peer problem subscale indicates significant levels of peer problems, and emotional symptoms were classified as high when the interviewees responses on the relevant subscale were 6 or higher. Similarly, peer problems were judged significant when scores on the peer problem scale were 4 or higher. On the conduct problems subscale, a score of 5 or higher indicates major conduct problems, and high levels of hyperactivity is marked by scores 8 or higher (SDQ, 2017).

The Children's Depression Inventory (Sitarenios \& Kovacs, 1999) is a well-tested and reliable instrument for assessing clinically relevant depressive symptoms in school-aged children and adolescents (Sun \& Wang, 2015). We assessed depressive symptoms as a third facet of internalizing problems. The inventory has been successfully implemented in Tanzanian settings (Hermenau et al., 2015; Traube et al., 2010). For each of the 27 items, the children were asked to pick one of three statements that best fit them. The different answer opportunities were rated 0,1 , and 2 , which resulted in the highest possible score of 54. High scores indicated more clinically severe depressive symptoms. In the current sample the Cronbach $\alpha$ coefficient was 0.70 . The Cohen $\kappa$ coefficient was $0.99(0.92-1)$. A cutoff point of 12 has been established as the ideal threshold discriminating children at risk of depression from nondepressed children (Kovacs, 2001; Traube et al., 2010). 
Table 1. Occurrences of neglect and abuse during the children's lifetime assessed with the Maltreatment and Abuse Chronology of Exposure Pediatric Interview

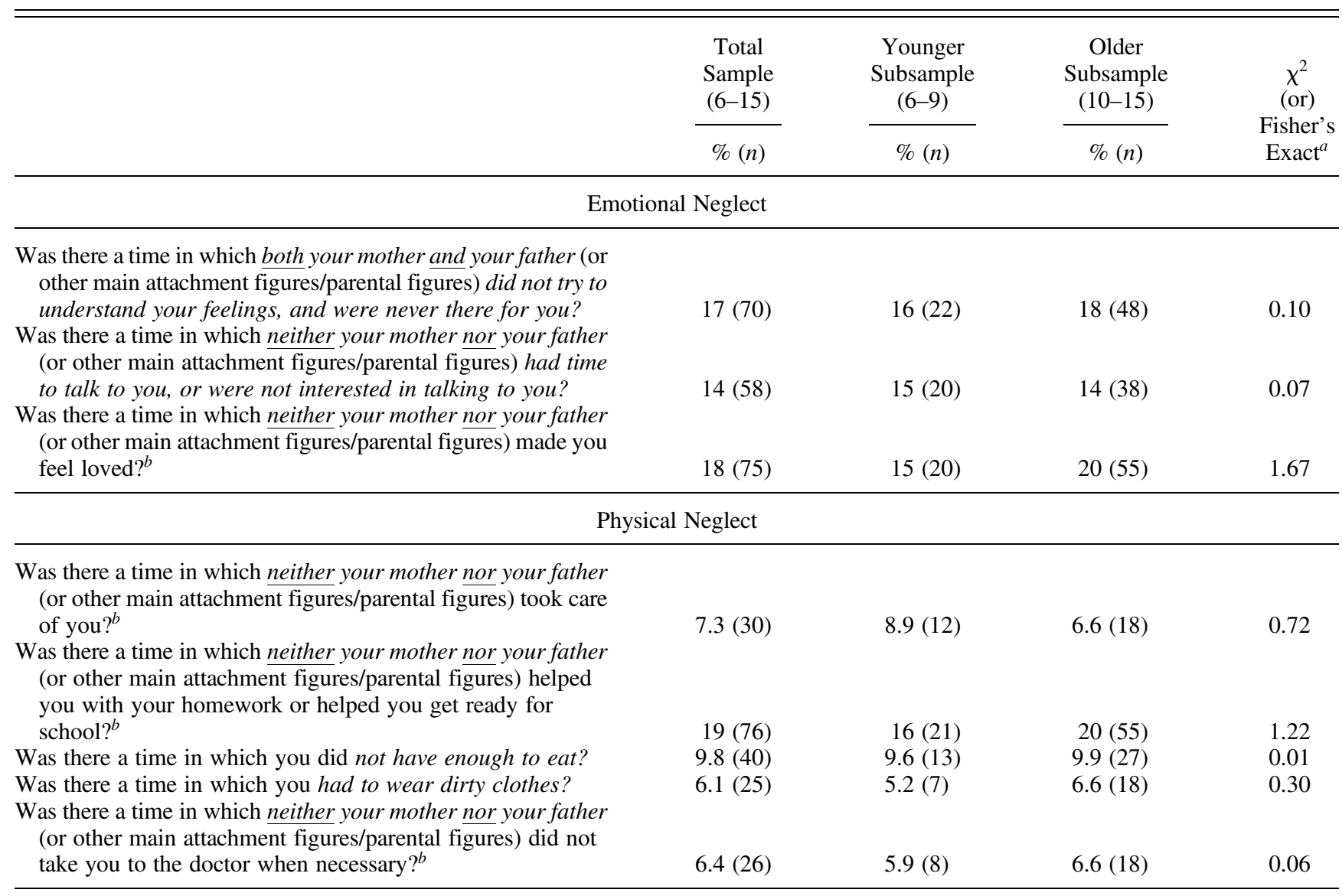

Peer Violence

Anybody called you names or said hurtful things, such as calling you "fat", "ugly," or "stupid" (more than a few times a year)?

Anybody said things behind your back, posted derogatory messages about you or spread rumors about you?

Anybody excluded you from activities or groups?

Anybody intentionally pushed, pinched, slapped, punched, or kicked you?

Anybody hit you so hard that you were injured?

\begin{tabular}{llll}
$43(177)$ & $45(61)$ & $42(116)$ & 0.30 \\
$49(199)$ & $53(72)$ & $46(127)$ & 1.77 \\
$37(151)$ & $47(64)$ & $32(87)$ & $9.52 * *$ \\
& & & \\
$54(219)$ & $55(74)$ & $53(145)$ & 0.13 \\
$16(67)$ & $19(25)$ & $15(42)$ & 0.67 \\
\hline
\end{tabular}

Family Violence

Has an adult at home called you names or said hurtful things such as calling you "fat," "ugly," or "stupid" (more than a few times a year)?

Has child at home called you names or said hurtful things such as calling you "fat," "ugly," or "stupid" (more than a few times a year)?

Has a child at home yelled/screamed at you (more than a few times a year)?

Has an adult at home locked you in a closet, attic, basement, garage, or another possibly narrow and dark place?

Has a child at home locked you in a closet, attic, basement, garage, or another possibly narrow and dark place?

Has an adult at home intentionally pushed, pinched, slapped, punched, or kicked you?

Has a child at home intentionally pushed, pinched, slapped, punched, or kicked you?

$\begin{array}{lccc}41(169) & 44(59) & 40(110) & 0.47 \\ 31(126) & 33(45) & 30(81) & 0.60 \\ 32(132) & 32(43) & 33(89) & 0.02 \\ 6.6(27) & 8.1(11) & 5.8(16) & 0.78 \\ 3.4(14) & 3(4) & 3.6(10) & >.999 \\ 66(270) & 73(98) & 63(172) & 3.89 * \\ 37(151) & 41(55) & 35(96) & 1.26\end{array}$


Table 1 (cont.)

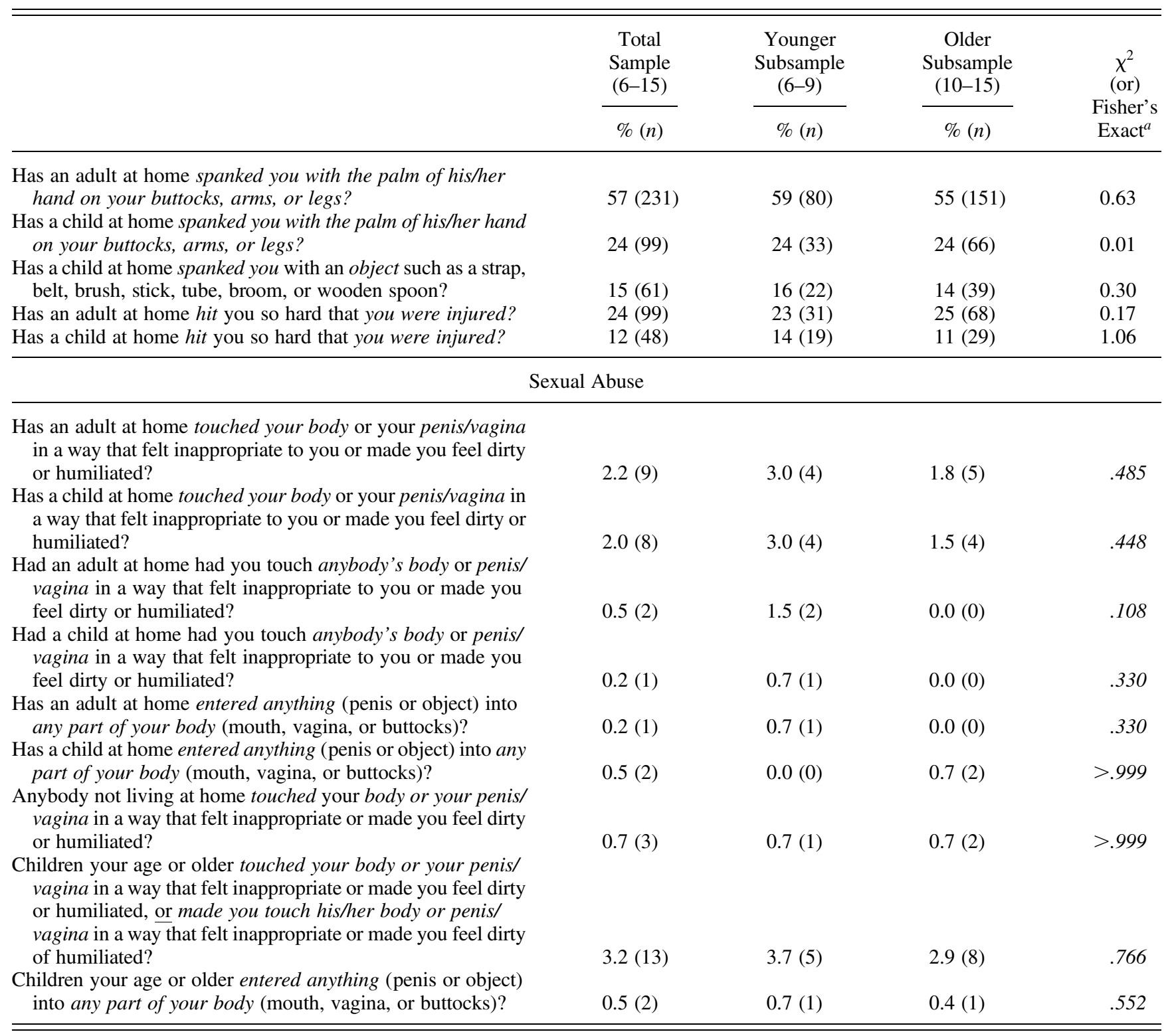

Note: Total sample, $N=409$; younger subsample, $N=135$; older subsample, $N=274$. Maltreatment and Abuse Chronology of Exposure Pediatric Interview (Isele et al., 2017).

${ }^{a}$ Fisher's exact $p$ values are in italic.

${ }^{b}$ Item was reversed for clarity.

$* p \leq .05 . * * p \leq .01 . * * * p \leq .001$.

The Reactive-Proactive Questionnaire (RPQ; Raine et al., 2006) assesses specific aggressive behavior in the previous 4 weeks. We estimated current aggressive behavior as a third facet of externalizing problems. The original RPQ consists of 23 items. However, slight changes were implemented in this study, following Hermenau et al. (2011). One of the items was not appropriate for our Tanzanian sample and was therefore removed (Item 18: "Made obscene phone calls for fun"). In addition, Item 9 was slightly rephrased to make it more understandable for the participants ("gang fight" was replaced with "fight"). The remaining 22 items had to be answered with $0=$ never, $1=$ sometimes, or $2=$ often. It was possible to obtain a score ranging from 0 to 44 . In the present sample the Cronbach $\alpha$ coefficient was 0.85 and the Cohen $\kappa$ coefficient was $0.99(0.94-1)$.

\section{Data analysis}

In total, 15 data sets were excluded from the structural equation model (SEM) due to missing data. To investigate the relationships between the exogenous variables neglect (physical and emotional) and exposure to violence (family violence, peer violence, and sexual abuse) and the endogenous variables internalizing problems (depressive symptoms, 
peer problems, and emotional symptoms) and externalizing problems (hyperactivity, aggressive symptoms, and conduct problems), we carried out a SEM analysis (see Figure 1 for a visual presentation) applying the robust weighted least squares means and variance adjusted (WLSMV) estimation. The WLSMV estimation was chosen because of the partly ordinal variables (Finney \& DiStefano, 2013). All measurement models showed a reasonable fit. All except one individual item significantly predicted the corresponding latent variables (see online-only supplementary Table S.1).

In our final SEM, we used sum scores for the different types of neglect, the different types of exposure to violence, the different types of externalizing problems, and the different types of internalizing problems, which is according to Little, Cunningham, Shahar, and Widaman (2002) justified, since we aimed to model the effects of the manifest variables on latent variables at a given level of generality. To make coefficients comparable, we fixed the factor loading of every first manifest variable of each latent variable to 1 as a constant value. Assessment of model fit was based on the following indices: chi-square $\left(\chi^{2}\right)$; comparative fit index (CFI), and the Tucker-Lewis index (TLI), both with values $>0.90$ indicating reasonable fit and $>0.95$ indicating good fit; root mean square error of approximation (RMSEA), with values $<0.08$ indicating reasonable fit and $<0.05$ indicating close fit (indicated also by PClose $>0.5$ : a "p-value" for testing the HO- hypothesis that the RMSEA is not greater than .05); standardized root mean square residual (SRMR), with values $<0.10$ indicating reasonable fit and $<0.05$ indicating close fit (Hu \& Bentler, 1999). For moderately complex models such as ours, a sample size of approximately 200 participants is considered as appropriate for SEM using the robust maximum likelihood estimation WLSMV (Nussbeck, Eid, \&
Lischetzke, 2006). Visual inspection showed no significant deviations from normality or linearity. The assumption of collinearity was met. Potential outliers were retained, since they were meaningful values with regard to content. Missing value analysis was carried out and revealed no other missing values except the ones reported above. For all directed hypotheses, we used one-tailed and for undirected hypothesis two-tailed $\alpha=0.05$. Regarding the standardized regression coefficients and on the basis of Cohen (1992), $\beta \geq 0.10$ indicated a small effect, $\beta \geq 0.30$ a medium effect, and $\beta \geq 0.50$ a large effect. Data was analyzed with IBM SPSS Statistics Version 21 for Mac OS X and R Version 3.2.1 for Mac OS X (R Core Team, 2016) and its lavaan package (Version 0.5-12; Rosseel, 2012).

\section{Results}

\section{Descriptive statistics}

The descriptive statistics are displayed in Table 2. In the current study, 31\% $(n=128)$ of the children had experienced at least one type of physical neglect and $31 \%(n=127)$ at least one type of emotional neglect. In total, 93\% $(n=379)$ of the children experienced at least one type of family violence, $78 \%(n=326)$ at least one event of peer violence, and $8.3 \%(n=34)$ at least one form of sexual abuse.

Regarding mental health problems, $18 \%$ reported a high level of emotional symptoms $(n=72)$ and of peer problems $(n=72)$, respectively. In total, $12 \%(n=50)$ showed a high level of conduct problems and $4 \%(n=15)$ a high level of hyperactivity. In the present sample, $14 \%(n=57)$ of the children were classified as being at risk of depression.

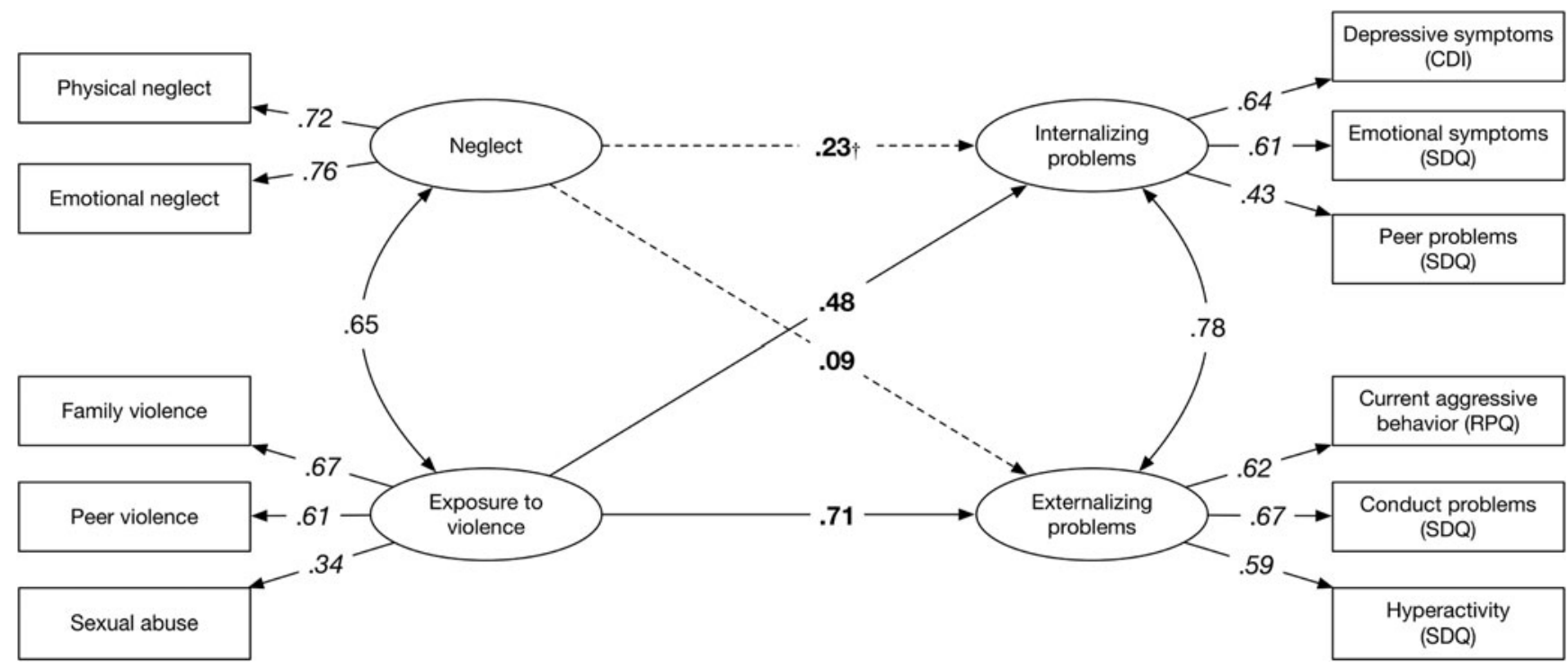

Figure 1. Structural equation model testing the direct association between neglect and internalizing problems and externalizing problems (total sample). Note: Standardized weighted least squares means and variance adjusted (WLSMV) estimates (regression weights in bold and factor loadings in italics) are depicted. Paths with dotted line are not significant ( $p>.05$, one-tailed). The path between neglect and internalizing problems depicts a trend with $p \leq .10$ (†p $\leq .10$, one-tailed). Error variables are omitted for clarity. 
Table 2. Descriptive statistics of all relevant variables

\begin{tabular}{|c|c|c|c|c|c|}
\hline & $\begin{array}{c}\text { Total } \\
\text { Sample } \\
(6-15)\end{array}$ & $\begin{array}{c}\text { Younger } \\
\text { Subsample } \\
(6-9)\end{array}$ & $\begin{array}{c}\text { Older } \\
\text { Subsample } \\
(10-15)\end{array}$ & & \\
\hline & $M(S D)$ & $M(S D)$ & $M(S D)$ & $t^{a}$ & $U^{b}$ \\
\hline \multicolumn{6}{|l|}{ No. of experienced types of } \\
\hline Physical neglect & $0.48(0.85)$ & $0.45(0.87)$ & $0.50(0.84)$ & & 17690.0 \\
\hline Emotional neglect & $0.50(0.86)$ & $0.46(0.84)$ & $0.51(0.87)$ & -0.61 & \\
\hline Family violence & $3.49(2.29)$ & $3.70(2.30)$ & $3.38(2.29)$ & 1.33 & \\
\hline Peer violence & $1.99(1.51)$ & $2.19(1.54)$ & $1.89(1.49)$ & $1.93 \dagger$ & \\
\hline Sexual abuse & $0.10(0.37)$ & $0.14(0.48)$ & $0.08(0.31)$ & & 17724.5 \\
\hline Current aggressive behavior (RPQ) & $8.53(5.74)^{c}$ & $9.64(6.11)$ & $7.97(5.48)^{d}$ & $2.79 * *$ & \\
\hline Conduct problems (SDQ) & $2.18(1.84)$ & $1.99(1.86)$ & $2.27(1.83)$ & -1.47 & \\
\hline Hyperactivity (SDQ) & $2.64(2.00)$ & $2.71(2.06)$ & $2.60(1.97)$ & 0.53 & \\
\hline Emotional symptoms (SDQ) & $3.19(2.31)$ & $3.24(2.10)$ & $3.16(2.42)$ & 0.14 & \\
\hline Peer problems (SDQ) & $2.09(1.63)$ & $2.16(1.65)$ & $2.05(1.62)$ & 0.67 & \\
\hline Depressive symptoms (CDI) & $6.76(4.57)$ & $6.65(4.40)$ & $6.82(4.66)$ & -0.34 & \\
\hline \multirow[t]{2}{*}{ Age } & $10.49(1.89)$ & $8.33(0.84)$ & $11.55(1.25)$ & $-30.84 * * *$ & \\
\hline & $\%(n)$ & $\%(n)$ & $\%(n)$ & $\chi^{2}$ & \\
\hline Sex (female) & 47.7 (195) & $57.8(78)$ & 42.7 (117) & $8.24 * *$ & \\
\hline Orphans & $21.8(89)$ & $14.1(19)$ & $25.5(70)$ & $6.99 * *$ & \\
\hline
\end{tabular}

Note: Total sample, $N=409$; younger subsample, $N=135$; older subsample, $N=274$.

${ }^{a} t, t$-test statistic.

${ }^{b} U$, Mann-Whitney $U$-test statistic.

${ }^{c} N=408$.

${ }^{d} N=273$

$\dagger p \leq .10 . * p \leq .05 . * * p \leq .01 . * * * p \leq .001$.

\section{Associations between neglect and internalizing and externalizing problems}

In the SEM we tested the association between child neglect and internalizing problems, as well as externalizing problems. In addition, we tested the association between exposure to violence and the two dependent variables to control for a possible influence of exposure to violence. All intercorrelations are displayed in online-only supplementary Table S.2. Our hypothesized model showed a good model fit, $\chi^{2}(38,394)=72.97, p$ $=.001, \mathrm{RMSEA}=0.048$ (90\% confidence interval $(\mathrm{CI}): 0.031$ -0.065$, PClose $=0.540), \mathrm{SRMR}=0.041, \mathrm{CFI}=0.955, \mathrm{TLI}$ $=0.935$. All manifest variables loaded significantly on the latent variables (see Table 3 ). Neglect was not significantly related to internalizing problems or externalizing problems. However, the effect size of the association between neglect and internalizing problems indicated a small effect and the association was significant if one allowed a $p$ value of .10. Exposure to violence correlated significantly with externalizing problems, indicating a large effect, as well as with internalizing problems, indicating a medium effect (see Figure 1).

\section{Differential associations in preadolescent and adolescent children}

We exploratorily tested our model again using a multigroup SEM analysis that divided the total sample in one group of younger children (ages 6-9) and one group of older children (ages 10-15). The division into these two groups was based on two considerations. First, previous research indicated that the prevalence of internalizing and externalizing problems changes with age (Costello, Mustillo, Erkanli, Keeler, \& Angold, 2003) and that adolescence may be a developmental period, in which the way mental health problems are experienced and reported may change greatly. For example, preadolescent children are more likely to show externalizing whereas adolescents are more likely to show internalizing mental health problems (Costello et al., 2003). Second, recent findings (Schalinski et al., 2016) showed that preschool (age 4-5) and preadolescent (age 8-9) ages may be particularly sensitive periods for the impact of neglect on mental health problems. By dividing the group into one preadolescent and one adolescent group, we aimed to compare the association between neglect and mental health problems in two groups that may differ greatly in the way they experienced and reported mental health problems. Moreover, we compared these associations between one group who experienced two potential sensitive periods, in which neglect may affect mental health strongly, and one group who experienced these two sensitive periods, too, but in addition may have been exposed to further experiences of neglect during adolescence.

We compared the two groups using $\chi^{2}$ or Fisher exact (small sample per cell) tests for categorical data and $t$, Welch (variance heterogeneity), or (nonparametric) Mann-Whitney 
Table 3. Weighted least squares means and variance adjusted estimates of the structural equation model (total sample)

\begin{tabular}{|c|c|c|c|c|}
\hline & $\begin{array}{l}\text { Unstand. } \\
\text { Est. }\end{array}$ & $S E$ & $\begin{array}{l}\text { Stand. } \\
\text { Est. }\end{array}$ & $\mathrm{CR}$ \\
\hline \multicolumn{5}{|c|}{ Latent Variables } \\
\hline \multicolumn{5}{|l|}{ Neglect } \\
\hline Emotional neglect & 1 & & 0.76 & \\
\hline Physical neglect & 0.94 & 0.12 & 0.72 & $7.71 * * *$ \\
\hline \multicolumn{5}{|l|}{ Exposure to violence } \\
\hline Family violence & 1 & & 0.67 & \\
\hline Peer violence & 0.54 & 0.07 & 0.61 & $7.78 * * *$ \\
\hline Sexual abuse & 0.07 & 0.01 & 0.34 & $6.75 * * *$ \\
\hline \multicolumn{5}{|l|}{ Internalizing problems } \\
\hline Depressive symptoms & 1 & & 0.64 & \\
\hline Emotional symptoms & 0.48 & 0.05 & 0.61 & $9.20 * * *$ \\
\hline Peer problems & 0.24 & 0.04 & 0.43 & $6.85 * * *$ \\
\hline \multicolumn{5}{|l|}{ Externalizing problems } \\
\hline Current aggressive behavior & 1 & & 0.62 & \\
\hline Conduct problems & 0.35 & 0.04 & 0.67 & $8.89 * * *$ \\
\hline Hyperactivity & 0.34 & 0.04 & 0.59 & $8.31 * * *$ \\
\hline \multicolumn{5}{|c|}{ Regressions } \\
\hline \multicolumn{5}{|l|}{ Internalizing problems } \\
\hline Neglect & 0.87 & 0.55 & 0.23 & $1.59 \dagger$ \\
\hline Exposure to violence & 0.83 & 0.24 & 0.48 & $3.46 * * *$ \\
\hline \multicolumn{5}{|l|}{ Externalizing problems } \\
\hline Neglect & 0.39 & 0.57 & 0.09 & 0.69 \\
\hline Exposure to violence & 1.47 & 0.31 & 0.71 & $4.82 * * *$ \\
\hline \multicolumn{5}{|c|}{ Covariances } \\
\hline Exposure to violence/neglect & 0.84 & 0.12 & 0.65 & $7.21 * * *$ \\
\hline Internalizing problems/externalizing problems & 3.83 & 0.84 & 0.78 & $4.59 * * *$ \\
\hline
\end{tabular}

Note: $n=394$. Unstand. Est., unstandardized weighted least squares means and variance adjusted estimates; Stand. Est., standardized weighted least squares means and variance adjusted estimates; CR, critical ratio. Model fit: $\chi^{2}(38, n=394)=72.97(p=$ .001 ), root mean square error of approximation $=0.048$ (90\% confidence interval: $0.031-0.065$, PClose (test of close fit) $=$ 0.540 ), standardized root mean square residual $=0.041$, comparative fit index $=0.955$, Tucker-Lewis index $=0.935$.

$\dagger p \leq .10$ (one tailed). $* p \leq .05$ (one tailed). $* * p \leq .01$ (one tailed). $* * * p \leq .001$ (one tailed).

$U$ tests for continuous data. The younger and older subsamples did not differ in their experiences of neglect. However, children in the younger sample were more likely to report being excluded by peers or being physically punished by their parents or caregivers. Yet, the two subsamples did not differ significantly concerning the number of experienced types of exposure to family violence, peer violence, or sexual abuse. The two subsamples did not differ regarding mental health problems, except for aggressive behavior, as reported in the RPQ. Here, the younger subsample reported a significantly higher level of aggressive behavior.

All measurement models showed a reasonable significance. The intercorrelations for both subsamples are provided in online-only supplementary Table S.2. The multigroup SEM showed a very good model fit, $\chi^{2}$ (76, younger subsample, $n=130$, older subsample, $n=264)=101.39, p=.027$, RMSEA $=0.041(90 \%$ CI: $0.015-0.061$, PClose $=0.745)$,
SRMR $=0.051, \mathrm{CFI}=0.966, \mathrm{TLI}=0.951 . \mathrm{In}$ both subgroups, all manifest variables loaded significantly on the latent variables when considering $\alpha=0.10$ (see Table 4). In the younger subgroup (ages 6-9), neglect was significantly related to internalizing problems, indicating a large effect. The association between neglect and externalizing problems was also significant, indicating a medium effect. Exposure to violence was not significantly related to externalizing problems or internalizing problems. However, the effect size of the association between exposure to violence and externalizing problems indicated a medium effect, and the association was significant when considering a $p$ value of 10 (see Figure 2). In the older subsample (ages 10-15), neglect was significantly related to neither internalizing nor externalizing problems. Exposure to violence correlated significantly with externalizing and with internalizing problems, both indicating large effects (see Table 4 and Figure 2). 
Table 4. Weighted least squares means and variance adjusted estimates of the multigroup structural equation model (grouping variable $=$ age)

\begin{tabular}{|c|c|c|c|c|}
\hline & Unstand. Est. & $S E$ & Stand. Est. & $\mathrm{CR}$ \\
\hline \multicolumn{5}{|c|}{ Younger Subsample (Age 6-9) } \\
\hline \multicolumn{5}{|c|}{ Latent Variables } \\
\hline \multicolumn{5}{|l|}{ Neglect } \\
\hline Emotional neglect & 1 & & 0.78 & \\
\hline Physical neglect & 0.78 & 0.24 & 0.60 & $3.31 * * *$ \\
\hline \multicolumn{5}{|l|}{ Exposure to violence } \\
\hline Family violence & 1 & & 0.66 & \\
\hline Peer violence & 0.57 & 0.16 & 0.62 & $3.53^{* * *}$ \\
\hline Sexual abuse & 0.05 & 0.03 & 0.16 & $1.49 \dagger$ \\
\hline \multicolumn{5}{|l|}{ Internalizing problems } \\
\hline Depressive symptoms & 1 & & 0.60 & \\
\hline Emotional symptoms & 0.52 & 0.11 & 0.65 & $4.91 * * *$ \\
\hline Peer problems & 0.28 & 0.06 & 0.45 & $4.35^{* * *}$ \\
\hline \multicolumn{5}{|l|}{ Externalizing problems } \\
\hline Current aggressive behavior & 1 & & 0.56 & \\
\hline Conduct problems & 0.40 & 0.08 & 0.75 & $5.24 * * *$ \\
\hline Hyperactivity & 0.30 & 0.07 & 0.50 & $4.61 * * *$ \\
\hline \multicolumn{5}{|c|}{ Regressions } \\
\hline \multicolumn{5}{|l|}{ Internalizing problems } \\
\hline Neglect & 2.01 & 0.85 & 0.59 & $2.37 * *$ \\
\hline Exposure to violence & 0.15 & 0.34 & 0.09 & 0.43 \\
\hline \multicolumn{5}{|l|}{ Externalizing problems } \\
\hline Neglect & 1.57 & 0.89 & 0.35 & $1.76^{*}$ \\
\hline Exposure to violence & 0.67 & 0.45 & 0.31 & $1.49 \dagger$ \\
\hline \multicolumn{5}{|c|}{ Covariances } \\
\hline Exposure to violence/neglect & 0.72 & 0.22 & 0.57 & $3.36^{* * *}$ \\
\hline Internalizing problems/externalizing problems & 4.43 & 1.48 & 0.79 & $2.99 * *$ \\
\hline \multicolumn{5}{|c|}{ Older Subsample (Age 10-15) } \\
\hline \multicolumn{5}{|c|}{ Latent Variables } \\
\hline \multicolumn{5}{|l|}{ Neglect } \\
\hline Emotional neglect & 1 & & 0.78 & \\
\hline Physical neglect & 0.95 & 0.16 & 0.74 & $6.05^{* * *}$ \\
\hline \multicolumn{5}{|l|}{ Exposure to violence } \\
\hline Family violence & 1 & & 0.64 & \\
\hline Peer violence & 0.55 & 0.08 & 0.59 & $6.80^{* * *}$ \\
\hline Sexual abuse & 0.09 & 0.01 & 0.46 & $6.16^{* * *}$ \\
\hline \multicolumn{5}{|l|}{ Internalizing problems } \\
\hline Depressive symptoms & 1 & & 0.66 & \\
\hline Emotional symptoms & 0.48 & 0.06 & 0.61 & $7.66^{* * *}$ \\
\hline Peer problems & 0.22 & 0.04 & 0.41 & $5.30^{* * *}$ \\
\hline \multicolumn{5}{|l|}{ Externalizing problems } \\
\hline Current aggressive behavior & 1 & & 0.65 & \\
\hline Conduct problems & 0.34 & 0.05 & 0.66 & $7.19^{* * *}$ \\
\hline Hyperactivity & 0.35 & 0.05 & 0.62 & $6.91^{* * *}$ \\
\hline \multicolumn{5}{|c|}{ Regressions } \\
\hline \multicolumn{5}{|l|}{ Internalizing problems } \\
\hline Neglect & -0.35 & 1.02 & -0.10 & -0.34 \\
\hline Exposure to violence & 1.50 & 0.47 & 0.81 & $3.19 * * *$ \\
\hline \multicolumn{5}{|l|}{ Externalizing problems } \\
\hline Neglect & -1.19 & 1.33 & -0.27 & -0.90 \\
\hline Exposure to violence & 2.38 & 0.70 & 1.11 & $3.39 * * *$ \\
\hline
\end{tabular}


Table 4 (cont.)

\begin{tabular}{lcccc}
\hline \hline & Unstand. Est. & $S E$ & Stand. Est. & \\
\hline & Covariances & & & \\
\hline Exposure to violence/neglect & 0.93 & 0.15 & 0.74 & $6.24^{* * *}$ \\
Internalizing problems/externalizing problems & 1.94 & 1.22 & 0.77 & $1.58 \dagger$ \\
\hline \hline
\end{tabular}

Note: Unstand. Est., unstandardized weighted least squares means and variance adjusted estimates; Stand. Est., standardized weighted least squares means and variance adjusted estimates; CR, critical ratio. Model fit: $\chi^{2}(76, n$ younger subsample $=130, n$ older subsample $=264),=101.39(p=$ .027 ), root mean square error of approximation $=0.041$ (90\% confidence interval: $0.015-0.061$, PClose (test of close fit $)=0.745)$, standardized root mean square residual $=0.051$, comparative fit index $=0.966$, Tucker-Lewis index $=0.951$.

$\dagger p \leq .10$ (one tailed). $* p \leq .05$ (one tailed). ${ }^{* *} p \leq .01$ (one tailed). $* * * p \leq .001$ (one tailed).

(a)

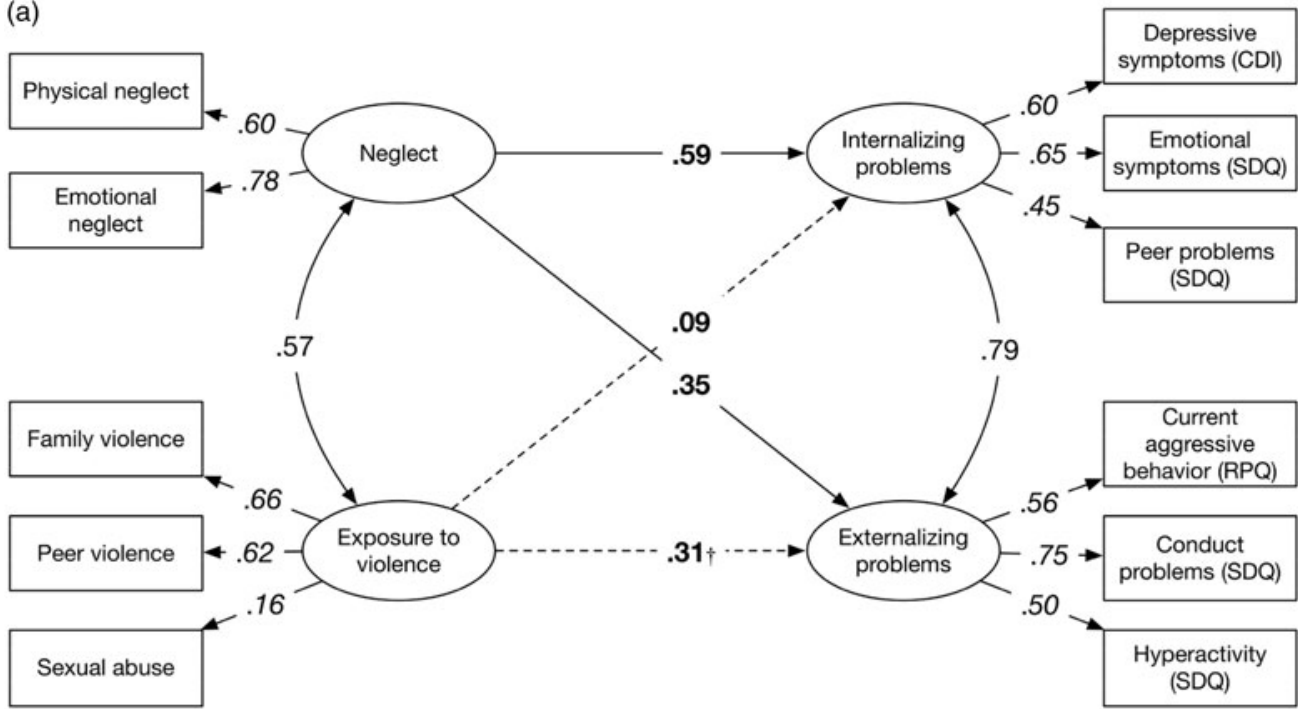

(b)

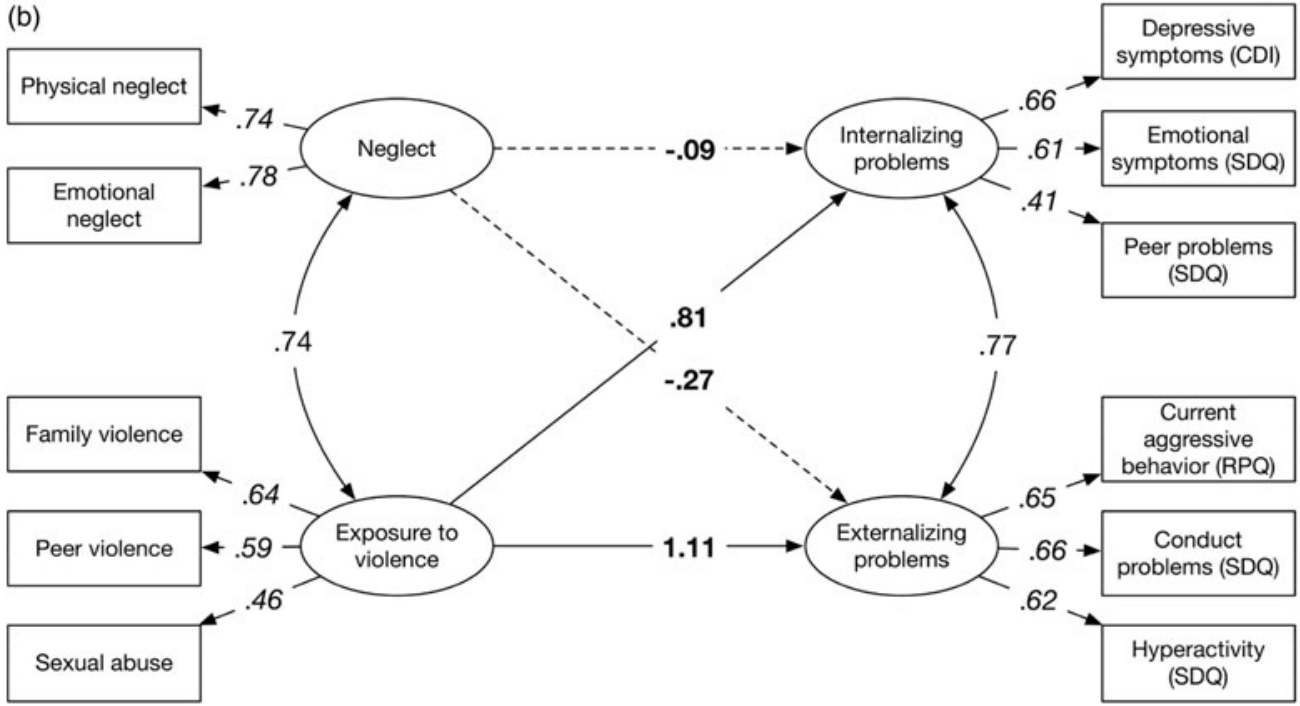

Figure 2. Multi-group structural equation model testing the direct association between neglect and internalizing problems and externalizing problems in a) the subsample of the younger children (age 6-9) and b) the subsample of the older children. Note: Standardized weighted least squares means and variance adjusted (WLSMV) estimates (regression weights in bold and factor loadings in italics) are depicted. Paths with dotted line are not significant $(p>.05$, one-tailed). The path between exposure to violence and externalizing problems in a) depicts a trend with $p \leq .10$ ( $\dagger p \leq$ .10 , one-tailed). Error variables are omitted for clarity. 


\section{Discussion}

We found a high rate of neglect in our sample. Almost every third child reported experiencing at least one form of physical or emotional neglect at some point in his or her life. The prevalence rates are higher than those presented in a meta-analysis on the global prevalence of neglect (Stoltenborgh et al., 2013). However, no study from the African continent was included in that meta-analysis.

Though the prevalence of neglect seems to be very high, studies investigating neglect in developing countries, particularly in sub-Saharan Africa, are still rare (Stoltenborgh et al., 2015). The few studies that focused on neglect in sub-Saharan Africa targeted orphans or other at-risk groups (e.g., Hermenau et al., 2015; Morantz et al., 2013). This was the first study examining neglect in a large community-based sample in sub-Saharan Africa. In low-resource countries, caregivers often do not have enough food to feed their families and many are unable to take their children to a doctor when they are ill, as they cannot afford it. As such, neglect is frequently unintentional. Nevertheless, regardless of the intention of parents and caregivers, the consequences are still severe (Mbagaya, 2010). For example, Hildyard and Wolfe (2002) found evidence that neglect, especially when it occurs early in life, can lead to mental health problems and cognitive dysfunction. As neglect has received little attention (McSherry, 2007), future research on this subtype of maltreatment is particularly necessary in resource-poor countries. One important reason for this is to contribute to a definition of neglect that fits the context and living realities in low-resource countries.

Following the developmental traumatology model (de Bellis, 2001) and social learning theory (Bandura, 1978; Hecker et al., 2014), we argue that experiences of abuse may be particularly associated with externalizing problems. In addition to this, the theory of learned helplessness (Abela, 2001; Abramson et al., 1978) may predict that neglect would be particularly related to internalizing problems. In line with these two predictions, prior research showed some support for the association between abuse and externalizing problems (Hecker et al., 2014; Manly et al., 2001; Sugaya et al., 2012) and also between neglect and internalizing problems (Bolger \& Patterson, 2001; Hildyard \& Wolfe, 2002; Kotch et al., 2008; Manly et al., 2001). We argue that deviating findings may be explained by the fact that many studies did not control for the potential co-occurrence of abuse and neglect. Nevertheless, in contrast to this idea and our hypothesis, we did not find a significant association between neglect and internalizing problems (though the effect size indicated a small effect) in the total sample. Exposure to violence was related to externalizing problems. It was also significantly related to internalizing problems, though our models controlled for the impact of neglect.

However, in contrast to this, for the younger subsample, the association between neglect and internalizing problems showed a large and significant effect. This is in accord with prior research findings investigating this association (Hildyard \& Wolfe, 2002; Manly et al., 2001; Widom et al.,
2007). These findings are congruent with previous findings that children who experienced more neglect in their lives had an increased risk of experiencing internalizing problems, like depressive symptoms, peer problems, and inferior emotion regulation skills. For example, neglected children reported higher levels of perceived external control. In addition, higher levels of perceived external control mediated the association between neglect and internalizing problems (Bolger $\&$ Patterson, 2001). Furthermore, neglect entails few social interactions and thereby a decreased chance of receiving social support (Manly et al., 2001). For example, children who experienced neglect at home have a smaller chance of compensating for the lack of social support through friends in general or peers at school. As we controlled for the influence of exposure to violence and abuse, our findings suggest a unique contribution of neglect to the overall consequences maltreatment, at least in the younger sample. Nonetheless, in the younger subsample, we also found a significant association between neglect and externalizing problems indicating a medium effect, which is in line with previous findings that neglected children show more aggressive behavior and violent criminal behavior compared to nonneglected children (e.g., Kotch et al., 2008; Manly et al., 2001).

In the older subsample, however, neglect was neither associated with internalizing nor with externalizing problems. These unexpected findings raise the question of whether the maltreatment type, the age, or an interaction of both best determine whether a child develops internalizing or externalizing problems. Previous research has already indicated that it is difficult to pinpoint the specific consequences following neglect and abuse (Korbin \& Krugman, 2014). In contrast to our hypothesis and a priori line of argument, our findings demonstrate the importance of considering the current age (potentially also the age of occurrence) in predicting whether a child develops internalizing or externalizing problems. Age is a contributing factor to future problems, or at least something to be controlled when investigating consequences of maltreatment. Future research is needed to investigate the interaction between current age, age at maltreatment and maltreatment type, and its effect on the development of different mental health problems. The sensitive period of exposure model (Schalinski et al., 2016; Teicher \& Samson, 2016) may be a helpful model to examine this unresolved question further.

\section{Practical implications and future research}

As neglect has received very little attention so far, the results of our current study emphasize the necessity of advancing research on neglect as one specific type of maltreatment. The association between neglect and internalizing and externalizing problems in the younger subsample underlines the importance of recognizing neglect as one discrete type of maltreatment in addition to exposure to violence and abuse. Yet, assessing something that is absent is complex and challenging compared to (visible) acts of violence and abuse. Therefore, instruments measuring neglect still need be improved. 
As suggested by Reynolds and Suzuki (2003) and supported by our study, cultural and particularly developmental aspects need to be considered when designing instruments that assess child neglect.

Besides the detrimental consequences for the children affected, high costs for the health care system could potentially be avoided (Maher, Corwin, Hodnett, \& Faulk, 2012) when people and institutions become aware of the major possible consequences. This is of special importance with regard to low-resource countries. A first step will be to inform caregivers, social workers, institutions, governmental organizations, and the population at large about the potentially deleterious consequences of neglectful acts. Support should be offered to parents and caregivers who may be at risk of neglecting the children in their care (Guterman, 1997). Enhanced knowledge in this field can lead to the development and implementation of effective prevention programs. Studies detecting risk factors of parents and caregivers for neglecting their children, such as the study conducted by Schumacher, Smith Slep, and Heyman (2001), could be used to develop prevention programs. Future research needs to extend studies like the current one with longitudinal and prospective approaches.

\section{Limitations}

This was the first study that investigated neglect in a large community-based sample of primary school-aged children in subSaharan Africa. Unlike many other studies, we aimed to disentangle the consequence of different types of maltreatment and exploratively considered the potential influence of current age. However, some limitations should be noted. The cross-sectional design does not allow for the establishment of causal directionality. For example, instead of neglect increasing the prevalence of internalizing problems, the reverse is also conceivable. However, past research has established depressive symptoms as one frequent consequence of neglect (Widom et al., 2007). Our sampling approach restricts the generalizability of our results. However, the sample was comparatively large and included children from different school grades and various social backgrounds. Nevertheless, our exploratory findings should be interpreted with caution considering the rather small sample size of the subsample of younger children. A replication of our findings in future studies is therefore required. We did not assess the socioeconomic status of the children's families or caregivers. This is a limitation as it denies us the possibility of investigating the influence of the socioeco- nomic status on mental health. A recent study by Hecker, Radtke, Hermenau, Papassotiropoulos, and Elbert (2016b) found support for the idea that children are capable of communicating their maltreatment experiences. Nevertheless, we cannot rule out a memory bias (i.e., recent maltreatment experiences are reported more reliably compared to those that occurred long time ago). Our sample consisted of about $20 \%$ orphans. Though this is comparable to the official figures from Tanzania, it may have affected the results in an unknown way. This limitation is particularly important considering that the number of orphans differed between the two subsamples. Moreover, we included children of the age of 6 years and older, though some of the instruments are only validated for older children. This may have impacted our results. However, as we assessed all variables by means of a structured expert interview, we tried to keep this potential impact to a minimum.

\section{Conclusions}

In concordance with previous findings, the current study found support for the idea that children who have experienced more neglect types are more likely to suffer from mental health problems. However, this association could only be detected in younger children (ages 6-9), whereas in older children (ages 10-15), mental health problems were significantly related to experiences of violence and abuse. Our findings indicate that the current age (and potentially the age at maltreatment) may influence the association between maltreatment type and the development of internalizing and/or externalizing problems. In addition, a more complex interaction between the developmental stage of the child (biologically and psychosocial) and the type of maltreatment (physical violence, abuse, or neglect) may be possible and should be investigated in the future. Furthermore, it could be examined whether effects of violence over time may cover the psychological wounds from early neglect. As neglect has been neglected thus far, future research needs to focus more on this type of maltreatment. Especially in low-resource countries, educational advertising and prevention programs with regard to neglect are of great importance in reducing the prevalence rates and serious long-term consequences. These steps would give the affected children a chance for a better future and age-appropriate, healthy development.

\section{Supplementary Material}

To view the supplementary material for this article, please visit https://doi.org/10.1017/S0954579417001882.

\section{References}

Abela, J. R. (2001). The hopelessness theory of depression: A test of the diathesis-stress and causal mediation components in third and seventh grade children. Journal of Abnormal Child Psychology, 29, 241-254. doi:10.1023/A:1010333815728.

Abramson, L. Y., Seligman, M. E., \& Teasdale, J. D. (1978). Learned helplessness in humans: Critique and reformulation. Journal of Abnormal Psychology, 87, 49-74.

Bandura, A. (1978). Social learning theory of aggression. Journal of Communication, 28, 12-29. doi:10.1111/j.1460-2466.1978.tb01621.x.

Barnett, D., Manly, J. T., \& Cicchetti, D. (1993). Defining child maltreatment: The interface between policy and research. In D. Cicchetti \& S. L. Toth (Eds.), Child abuse, child development, and social policy: Advances in applied developmental psychology (Vol. 8, pp. 7-73). Norwood, NJ: Ablex. 
Bolger, K. E., \& Patterson, C. J. (2001). Pathways from child maltreatment to internalizing problems: Perceptions of control as mediators and moderators. Development and Psychopathology, 13, 913-940.

Cohen, J. (1992). A power primer. Psychological Bulletin, 112, 155-159. doi:10.1037/0033-2909.112.1.155.

Costello, E. J., Mustillo, S., Erkanli, A., Keeler, G., \& Angold, A. (2003). Prevalence and development of psychiatric disorders in childhood and adolescence. Archives of General Psychiatry, 60, 837-844.

Danese, A., \& Tan, M. (2014). Childhood maltreatment and obesity: Systematic review and meta-analysis. Molecular Psychiatry, 19, 544-554. doi:10.1038/mp.2013.54.

de Bellis, M. D. (2001). Developmental traumatology: The psychobiological development of maltreated children and its implications for research, treatment, and policy. Development and Psychopathology, 13, 539564. doi:10.1017/S0954579401003078.

Dubowitz, H. (2007). Understanding and addressing the "neglect of neglect": Digging into the molehill. Child Abuse and Neglect, 31, 603-606. doi:10.1016/j.chiabu.2007.04.002

Dubowitz, H. (2013). Neglect in children. Pediatric Annals, 42, 73-77. doi:10.3928/00904481-20130326-11.

Dubowitz, H., \& Bennett, S. (2007). Physical abuse and neglect of children. Lancet, 369, 1891-1899. doi:10.1016/S0140-6736(07)60856-3.

Dubowitz, H., Newton, R. R., Litrownik, A. J., Lewis, T., Briggs, E. C., Thompson, R., . . Feerick, M. M. (2005). Examination of a conceptual model of child neglect. Child Maltreatment, 10, 173-189. doi:10.1177/ 1077559505275014.

Finkelhor, D., Ormrod, R. K., \& Turner, H. A. (2007). Poly-victimization: A neglected component in child victimization. Child Abuse and Neglect, 31,7-26. doi:10.1016/j.chiabu.2006.06.008.

Finney, S. J., \& DiStefano, C. (2013). Nonnormal and categorical data in structural equation modeling. In G. R. Hancock \& R. O. Mueller (Eds.), Structural equation modeling: A second course (2nd ed., pp. 439-492). Greenwich, CT: Information Age.

Gershoff, E. T. (2002). Corporal punishment by parents and associated child behaviors and experiences: A meta-analytic and theoretical review. Psychological Bulletin, 128, 539-579. doi:10.1037//0033-2909.128.4.539.

Gilbert, R., Widom, C. S., Browne, K., Fergusson, D., Webb, E., \& Janson, S. (2009). Burden and consequences of child maltreatment in high-income countries. Lancet, 373, 68-81. doi:10.1016/S0140-6736(08)61706-7.

Goodman, R. (2001). Psychometric properties of the Strengths and Difficulties Questionnaire. Journal of the American Academy of Child \& Adolescent Psychiatry, 40, 1337-1345. doi:10.1097/00004583-200111000-00015.

Goodman, R., Meltzer, H., \& Bailey, V. (1998). The Strengths and Difficulties Questionnaire: A pilot study on the validity of the self-report version. European Child and Adolescent Psychiatry, 7, 125-130. doi:10.1007/ s007870050057.

Guterman, N. B. (1997). Early prevention of physical child abuse and neglect: Existing evidence and future directions. Child Maltreatment, 2, 12-34. doi:10.1177/1077559597002001003.

Hecker, T., Hermenau, K., Isele, D., \& Elbert, T. (2014). Corporal punishment and children's externalizing problems: A cross-sectional study of Tanzanian primary school students. Child Abuse and Neglect, 38, 884892. doi:10.1016/j.chiabu.2013.11.007.

Hecker, T., Hermenau, K., Salmen, C., Teicher, M., \& Elbert, T. (2016a). Harsh discipline relates to internalizing problems and cognitive functioning: Findings from a cross-sectional study with school children in Tanzania. BMC Psychiatry, 16, 118. doi:10.1186/s12888-016-0828-3.

Hecker, T., Radtke, K., Hermenau, K., Papassotiropoulos, A., \& Elbert, T. (2016b). Associations between child abuse, mental health and epigenetic modifications in the proopiomelanocortin gene (POMC): A study with children in Tanzania. Development and Psychopathology, 28 (4.2), 1401-1412. doi:10.1017/S0954579415001248.

Hermenau, K., Eggert, I., Landolt, M. A., \& Hecker, T. (2015). Neglect and perceived stigmatization impact psychological distress of orphans in Tanzania. European Journal of Psychotraumatology, 6, 28617. doi:10.3402/ ejpt.v6.28617.

Hermenau, K., Hecker, T., Ruf, M., Schauer, E., Elbert, T., \& Schauer, M. (2011). Childhood adversity, mental ill-health and aggressive behavior in an African orphanage: Changes in response to trauma-focused therapy and the implementation of a new instructional system. Child and Adolescent Psychiatry and Mental Health, 5, 29. doi:10.1186/1753-2000-5-29.

Hildyard, K. L., \& Wolfe, D. A. (2002). Child neglect: Developmental issues and outcomes. Child Abuse and Neglect, 26, 679-695. doi:10.1016/ s0145-2134(02)00341-1.
Hu, L., \& Bentler, P. M. (1999). Cutoff criteria for fit indexes in covariance structure analysis: Conventional versus new alternatives. Structural Equation Modeling, 6, 1-55. doi:10.1080/10705519909540118.

International Monetary Fund. (2007). World economic outlook: April 2007. Washington, DC: Author.

Isele, D., Hecker, T., Hermenau, K., Elbert, T., Ruf-Leuschner, M., Moran, J., ... Schauer, M. (2017). Assessing childhood adversities: The pediatric Maltreatment and Abuse Chronology of Exposure Interview. Unpublished manuscript.

Jud, A., Lips, U., \& Landolt, M. A. (2010). Characteristics associated with maltreatment types in children referred to a hospital child protection team. European Journal of Pediatrics, 169, 173-180. doi:10.1007/ s00431-009-1001-5.

Korbin, J. E., \& Krugman, R. D. (2014). The handbook of child maltreatment. Dordrecht, the Netherlands: Springer.

Kotch, J. B., Lewis, T., Hussey, J. M., English, D., Thompson, R., Litrownik, A. J., . . Dubowitz, H. (2008). Importance of early neglect for childhood aggression. Pediatrics, 121, 725-731. doi:10.1542/peds.2006-3622.

Kovacs, M. (2001). Children's Depression Inventory (CDI): Technical manual. North Tonawanda, NY: Multi-Health Systems.

Leeb, R. T., Paulozzi, L., Melanson, C., Simon, T., \& Arias, I. (2008). Child maltreatment surveillance: Uniform definitions for public health and recommended data elements. . Atlanta, GA: Centers for Disease Control and Prevention. Retrieved from http://www.cdc.gov/violenceprevention/pub/ cmp-surveillance.html

Little, T. D., Cunningham, W. A., Shahar, G., \& Widaman, K. F. (2002). To parcel or not to parcel: Exploring the question, weighing the merits. Structural Equation Modeling, 9, 151-173. doi:10.1207/S15328007SEM0902_1.

Maher, E. J., Corwin, T. W., Hodnett, R., \& Faulk, K. (2012). A cost-savings analysis of a statewide parenting education program in child welfare. Research on Social Work Practice, 22, 615-625. doi:10.1177/1049731512449873.

Manly, J. T., Kim, J. E., Rogosch, F. A., \& Cicchetti, D. (2001). Dimensions of child maltreatment and children's adjustment: Contributions of developmental timing and subtype. Development and Psychopathology, 13, 759-782.

Mbagaya, C. V. (2010). Child maltreatment in Kenya, Zambia, and the Netherlands: A crosscultural comparison of prevalence, psychopathological sequelae, and mediation by PTSS (Unpublished doctoral dissertation, Leiden University).

McNally, R. J. (2006). Cognitive abnormalities in post-traumatic stress disorder. Trends in Cognitive Sciences, 10, 271-277. doi:10.1016/j.tics. 2006.04.007.

McSherry, D. (2007). Understanding and addressing the "neglect of neglect": Why are we making a mole-hill out of a mountain? Child Abuse and Neglect, 31, 607-614. doi:10.1016/j.chiabu.2006.08.011.

Mennen, F. E., Kim, K., Sang, J., \& Trickett, P. K. (2010). Child neglect: Definition and identification of youth's experiences in official reports of maltreatment. Child Abuse and Neglect, 34, 647-658. doi:10.1016/ j.chiabu.2010.02.007.

Mills, R., Alati, R., O'Callaghan, M., Najman, J. M., Williams, G. M., Bor, W., \& Strathearn, L. (2011). Child abuse and neglect and cognitive function at 14 years of age: Findings from a birth cohort. Pediatrics, 127, 4-10. doi:10.1542/peds.2009-3479.

Morantz, G., Cole, D. C., Ayaya, S., Ayuku, D., \& Braitstein, P. (2013). Maltreatment experiences and associated factors prior to admission to residential care: A sample of institutionalized children and youth in western Kenya. Child Abuse and Neglect, 37, 778-787. doi:10.1016/j.chiabu. 2012.10.007.

Norman, R. E., Byambaa, M., De, R., Butchart, A., Scott, J., \& Vos, T. (2012). The long-term health consequences of child physical abuse, emotional abuse, and neglect: A systematic review and meta-analysis. PLOS Medicine, 9, e1001349. doi:10.1371/journal.pmed.1001349.

Nussbeck, F. W., Eid, M., \& Lischetzke, T. (2006). Analysing multitrait-multimethod data with structural equation models for ordinal variables applying the WLSMV estimator: What sample size is needed for valid results? British Journal of Mathematical and Statistical Psychology, 59, 195213. doi:10.1348/000711005X67490.

Paolucci, E. O., Genuis, M. L., \& Violato, C. (2001). A meta-analysis of the published research on the effects of child sexual abuse. Journal of Psychology, 135, 17-36. doi:10.1080/00223980109603677.

Raine, A., Dodge, K. A., Loeber, R., Gatzke-Kopp, L., Lynam, D., Reynolds, C., . . Liu, J. (2006). The Reactive-Proactive Aggression Questionnaire: Differential correlates of reactive and proactive aggression in adolescent boys. Aggressive Behavior, 32, 159-171. doi:10.1002/ab20115. 
R Core Team. (2016). R: A language and environment for statistical computing [Computer software]. Vienna: R Foundtion for Statistical Computing.

Reynolds, C. R., \& Suzuki, L. A. (2003). Bias in psychological assessment: An empirical review and recommendations. In C. R. Reynolds \& M. C. Ramsay (Eds.), Handbook of psychology (pp. 82-113). New York: Wiley.

Rosseel, Y. (2012). lavaan: An R package for structural equation modeling. Journal of Statistical Software, 48, 1-36. doi:10.18637/jss.v048.i02.

Schalinski, I., Teicher, M. H., Nischk, D., Hinderer, E., Müller, O., Rockstroh, B., . . . Rockstroh, B. (2016). Type and timing of adverse childhood experiences differentially affect severity of PTSD, dissociative and depressive symptoms in adult inpatients. BMC Psychiatry, 16, 295. doi:10. 1186/s12888-016-1004-5.

Schumacher, J. A., Smith Slep, A. M., \& Heyman, R. E. (2001). Risk factors for child neglect. Aggression and Violent Behavior, 6, 231-254. doi:10.1016/S1359-1789(00)00024-0.

SDQ. (2017). SDQ: Official webpage. Retrieved April 25, 2017, from http:/ www.sdqinfo.org/py/sdqinfo/b3.py?language=Englishqz(USA).

Sedlak, A. J., Mettenburg, J., Basena, M., Petta, I., McPherson, K., Greene, A., \& Li, S. (2010). Fourth National Incidence Study of Child Abuse and Neglect (NIS-4): Report to Congress. Washington, DC: Department of Health and Human Services, Administration for Children and Families. Retrieved from http://www.acf.hhs.gov/sites/default/files/opre/nis4_ report_congress_full_pdf_jan2010.pdf

Sitarenios, G., \& Kovacs, M. (1999). Use of the Children's Depression Inventory. In M. E. Maruish (Ed.), The use of psychological testing for treatment planning and outcomes assessment (2nd ed., pp. 267-298). Mahwah, NJ: Erlbaum.

Spratt, E. G., Friedenberg, S. L., Swenson, C. C., LaRosa, A., De Bellis, M. D., Macias, M. M., . . Brady, K. T. (2012). The effects of early neglect on cognitive, language, and behavioral functioning in childhood. Psychology, 3, 175-182. doi:10.4236/psych.2012.32026.

Stoltenborgh, M., Bakermans-Kranenburg, M. J., Alink, L. R. A., \& van IJzendoorn, M. H. (2015). The prevalence of child maltreatment across the globe: Review of a series of metaanalyses. Child Abuse Review, 24, 3750. doi:10.1002/car.2353.

Stoltenborgh, M., Bakermans-Kranenburg, M. J., \& van IJzendoorn, M. H. (2013). The neglect of child neglect: A meta-analytic review of the prevalence of neglect. Social Psychiatry and Psychiatric Epidemiology, 48, 345-355. doi:10.1007/s00127-012-0549-y.

Sugaya, L., Hasin, D. S., Olfson, M., Lin, K., Grant, B. F., \& Blanco, C. (2012). Child physical abuse and adult mental health: A national study. Journal of Traumatic Stress, 25, 384-392. doi:10.1002/jts.21719.
Sun, S., \& Wang, S. (2015). The Children's Depression Inventory in worldwide child development research: A reliability generalization study. Jour nal of Child and Family Studies, 24, 2352-2363. doi:10.1007/s10826014-0038-X.

Teicher, M. H., \& Parigger, A. (2015). The "Maltreatment and Abuse Chronology of Exposure" (MACE) scale for the retrospective assessment of abuse and neglect during development. PLOS ONE, 10, e0117423. doi:10.1371/journal.pone.0117423.

Teicher, M. H., \& Samson, J. A. (2016). Annual research review: Enduring neurobiological effects of childhood abuse and neglect. Journal of Child Psychology and Psychiatry, 57, 241-266. doi:10.1111/jcpp.12507.

Traube, D., Dukay, V., Kaaya, S., Reyes, H., \& Mellins, C. (2010). Cross-cultural adaptation of the Child Depression Inventory for use in Tanzania with children affected by HIV. Vulnerable Children and Youth Studies, 5, 174-187. doi:10.1080/17450121003668343.

UNICEF. (2011). Violence against children in Tanzania: Results from a national survey, 2009. Dar es Salaam, Tanzania: Author. Retrieved from http://www.unicef.org/media/files/VIOLENCE_AGAINST_CHILDREN_IN_TANZANIA_REPORT.pdf

US Department of Health and Human Services. (2010). Child maltreatment 2009. Washington, DC: US Department of Health and Human Services, Administration for Children and Families Administration on Children, Youth and Families, Children's Bureau. Retrieved from https://www. acf.hhs.gov/sites/default/files/cb/cm2009.pdf

US Department of Health and Human Services. (2012). Child maltreatment, 2011. Washington, DC: US Department of Health and Human Services, Administration for Children and Families Administration on Children, Youth and Families, Children's Bureau. Retrieved from http://www.acf. hhs.gov/sites/default/files/cb/cm11.pdf

Widom, C. S., DuMont, K., \& Czaja, S. J. (2007). A prospective investigation of major depressive disorder and comorbidity in abused and neglected children grown up. Archives of General Psychiatry, 64, 49-56. doi:10. 1001/archpsyc.64.1.49.

Widom, C. S., \& Maxfield, M. G. (2001). An update on the "Cycle of Violence" (NCJ 184894). Washington, DC: National Institute of Justice. Retrieved from ascdwc.com/wpcontent/\%0Auploads/2014/02/https:_www. ncjrs.gov_pdffiles1_nij_184894.pdf

Wolock, I., \& Horowitz, B. (1984). Child maltreatment as a social problem: The neglect of neglect. American Journal of Orthopsychiatry, 54, 530 543. doi:10.1111/j.1939-0025.1984.tb01524.x. 